International Journal of Child, Youth and Family Studies (2013) 1: 119-135

\title{
BUILDING SAFE COMMUNITIES FROM THE START: THE UPSTART PARENT SURVEY
}

\author{
Dawne Clark, Leslie Barker, and Karen Benzies
}

\begin{abstract}
Healthy child development sets the foundation for the lifelong trajectory of children and the very health of our society. Effective parenting supports optimal child development in all its domains. The UpStart Parent Survey was developed to help agencies that provide prevention-focused parenting programs (P-FPPs) determine the successful parental acquisition of common outcomes known to predict effective parenting. The purposes of this initial project, Building Safe Communities from the Start: The Upstart Parent Survey, were threefold: (a) to determine the psychometric properties of the tool, (b) to determine the feasibility of using the UpStart Parent Survey in P-FPPs, and (c) to examine the effectiveness of P-FPPs using the UpStart Parent Survey. This article addresses the latter two purposes.
\end{abstract}

Keywords: parenting, preschool children, program evaluation, feasibility studies, mixed methods

Acknowledgements: We thank the agencies who participated in Building Safe Communities from the Start: The UpStart Parent Survey: Alberta Health Services, Parents and Children Together (PACT), Calgary Urban Project Society (CUPS), Calgary Immigrant Women's Association (CIWA), Families Matter, and Attachment Parenting Canada. These agencies supported the development of the UpStart Parent Survey from its inception. Funding was provided by UpStart: Champions for Children and Youth of the United Way of Calgary and Area, and the Centre for Criminology and Justice Research at Mount Royal University. Finally, we extend our appreciation to research assistants Bree Crone, Kristen Duke, and Preet Dhesi from Mount Royal University, and Jen Smith and Hilary Rancourt from the University of Calgary.

Dawne Clark, Ph.D. (the Corresponding Author) is a Professor and Director of the Centre for Child Well-Being, Mount Royal University, 4825 Mount Royal Gate SW, Calgary Alberta, Canada, T3E 6K6, (403) 440-6941. E-mail: dclark@mtroyal.ca

Leslie Barker, RN, BScN is a Research Project Coordinator with the provincial Early Childhood Team, Health Promotion, Disease and Injury Prevention, Alberta Health Services. E-mail: Leslie.barker@albertahealthservices.ca

Karen Benzies, RN, Ph.D. is a Professor in the Faculty of Nursing, University of Calgary, 2500 University Drive NW, Calgary, Alberta, Canada, T2N 1N4. E-mail: benzies@ucalgary.ca 
In the human lifespan, the period before birth up to about 5 years of age encompasses the most rapid growth and brain development (Knudson, 2004; Shonkoff, 2003). The basic architecture of the human brain is constructed through an ongoing process that begins before birth and continues to early adulthood. Early experiences literally shape how the brain is built (Kolb, Gibb, \& Robinson, 2003). The brain ultimately determines language, behaviour, mental and physical health, and a child's capacity to learn throughout life (Shonkoff, 2003). All areas of development are inextricably linked, each dependent on the other. A strong foundation starting in infancy increases the probability of positive outcomes for children; a weak foundation increases the odds of later difficulties.

Parents are the most significant influence on how their children grow and learn (Shonkoff, 2003). All parents need information, support, and guidance to enhance their children's development. Recent research shows that there is a meaningful gap in what parents need to know to positively impact their children's development (Rikhy, Tough, Trute, Benzies, Kehler, \& Johnston, 2010). Parenting programs to promote healthy development of young children can offer parents an opportunity to learn how to help their children grow and learn, learn from one another, build vital support networks, and create a strong sense of community (Kaminsky, Valle, Filene, \& Boyle, 2008).

Effective parenting is a key contributor to healthy child development (Shonkoff, 2003). Parenting is primarily a task of socializing children within an ecological context (White, 2005). Effective parenting refers to carrying out the responsibilities of rearing and interacting so that the child is well prepared to realize his or her full potential (White, 2005). Several decades of research have shown a consistent relationship between the quality of parenting and the developmental outcomes of children (Lundahl, Risser, \& Lovejoy, 2006; O'Connor, 2002), particularly behavioural development (Benzies, Keown, \& Magill-Evans, 2009; Nagin \& Tremblay, 2001). In a longitudinal sub-sample of children $(N=975)$ drawn from the National Longitudinal Survey of Children and Youth (NLSCY), Benzies and colleagues (2009) determined that ineffective or hostile parenting had not only an immediate effect on children's physical aggression, but also a sustained effect that carried forward in time at least to the age of 6 years. In low-income families, time spent with the child and stimulating resources are predictors of cognitive and language outcomes, while parenting is a key mediator of problematic social behaviour (Mistry, Benner, Biesanz, Clark, \& Howes, 2010). Using structural equation modeling with children $(N=1,851)$ from Early Head Start, Mistry and colleagues (2002) highlighted the detrimental effects of exposure to negative parenting practices, particularly during infancy. While the majority of children "grow out" of aggressive behaviours in early childhood, many do not and continue with an escalating trajectory of physical aggression that can result in later criminal behaviours and justice system involvement (Tremblay et al., 2004). Ineffective parenting is significantly related to increased risk of school failure and of the child developing conduct problems which increase the risk for becoming involved in anti-social, aggressive, and offending behaviour (Gardner, Burton, \& Klimes, 2006; O’Connor, 2002). Behavioural problems in children are linked to increased costs to government systems, including education, social services, and justice (Scott, Knapp, Henderson, \& Maughan, 2001). 
By age 6 years, approximately 25\% of Canadian children have one or more physical, social/emotional, or cognitive developmental concerns likely to cause problems in later life (McCain, Mustard \& Shanker, 2007). Traditional beliefs about who is at risk have been challenged in that the NLSCY has shown that 70\% of these children live in two-parent, middleincome families (McCain et al., 2007), a group not usually thought to need parenting information and support. Families are the first point for the socialization of children to the norms and rules of society. Increasingly, efforts to properly equip children for the demands of today's society are being threatened because families are challenged by lack of knowledge, increasing external time demands, and socio-economic pressures (Armstrong, Birnie-Lefcovitch, \& Ungar, 2005; Rikhy, et al., 2010). Parenting programs can be a valuable source of information and support.

There exists a continuum of parenting programs that ranges from promotion/prevention at one end, to intervention/treatment at the other. The definitions of terms on this continuum are borrowed from the field of population and public health where primary prevention is the foundation (Stewart, 2000). Primary prevention is population focused and is aimed at education, increasing people's resiliency, and decreasing or eliminating the underlying causes of health and social problems. The focus of primary prevention is on health, not illness. The goal of secondary prevention is to reduce the number of existing cases by working with clients who have risk factors for the development of disease or who are in the early stages of clinical problems. Tertiary preventions focus on clients with known clinical problems with the intention of preventing conditions from worsening. In the context of parenting programs, primary prevention focuses on developing parental knowledge, skills, competence, and healthy relationships between parents and their children from the outset, rather than waiting to treat problems once they occur. Secondary prevention focuses on families who have identified risks for poorer outcomes but who are still not in the clinical problem zone. Tertiary prevention focuses on families who have identified clinical problems, such as parental mental illness or child conduct disorders.

The term "prevention-focused parenting program” (P-FPP) is used to describe parenting programs that are primarily focused on providing education and support, and promoting healthy child development - at either the primary or secondary prevention level. P-FPPs offer parents a chance to learn from each other and from an experienced professional about ways to help their children grow and learn, and how to cope with typical parenting challenges. In the process, parents have the opportunity to build more supportive parent/child relationships, and create vital social support networks and a stronger sense of community (Kaminsky et al., 2008). Evidencebased P-FPPs are well positioned to provide the information and supports that parents need to support healthy child development in all its domains decreasing the likelihood of problematic social behaviours. While not all problems can be prevented, current evidence suggests that when parents are more knowledgeable about what to expect, have effective ways to respond, and know when to be concerned, they are less likely to have a problematic relationship with their child (Canadian Association of Family Resource Programs [FRP Canada], 2011; Rikhy et al., 2010). P-FPPs provide education and support to parents thereby increasing the likelihood of positively influencing parent/child relationships and child development. 
International Journal of Child, Youth and Family Studies (2013) 1: 119-135

In the current economic climate, there has been an increased demand for accountability. Although most P-FPPs are designed on a solid base of theory (Kaminski et al., 2008), evaluation of most P-FPPs in Canada has not been scientifically rigorous (McLennan \& Lavis, 2006). Limited evaluative evidence of P-FPPs constrains decisions about program development and quality improvement. In addition, most evaluation data for parenting programs come from intervention-focused programs for families with children with serious problems (Sanders, Markie-Dadds, Tully, \& Bor, 2000; Webster-Stratton \& Reid, 2003). While the effectiveness of these intervention-focused programs in treating problems is well documented, these results cannot necessarily be applied to P-FPPs as the focus of this type of programming is to promote healthy early relationships by understanding and effectively managing with challenging normative behaviour, thus preventing problematic patterns of coping before they occur. Thus, an appropriate research agenda and evaluation tools for P-FPPs are needed.

Rigorous evaluation requires the use of reliable and valid instruments. Frequently, program providers and program evaluators have conflicting goals that affect evaluation. Program providers want evaluations that are as unobtrusive as possible, take up minimal program time, constitute minimum respondent burden, do not alienate respondents, are inexpensive and easy to analyze and report, and give useful information for quality improvement (Griner Hill \& Betz, 2005). On the other hand, program evaluators want to obtain meaningful data that present an accurate assessment of program outcomes using measurement tools with strong psychometric properties, including reliability and validity (National Forum on Early Childhood Program Evaluation, 2007). If the measurement of program outcomes is burdensome, it may actually interfere with outcomes by annoying participants or using important program time (Sibthorp, Paisley, Gookin, \& Ward, 2007; Moore \& Tanais, 2009). The ideal tool for program providers and program evaluators is a brief, parent- and provider-friendly tool with strong psychometric properties.

The UpStart Parent Survey was designed by a partnership of community agencies, researchers, and policy-makers - through UpStart: Champions for Children and Youth of the United Way of Calgary and Area - to assess the Common Outcome Indicators of parenting programs as identified by the Alberta Centre for Child, Family and Community Research or ACCFCR (2007). These indicators are known to predict effective parenting and more positive parent/child relationships, and include parenting knowledge and skills, self-efficacy, mental health, social support, parenting stress, and family functioning.

The Building Safe Communities from the Start: The UpStart Parent Survey project had a threefold purpose:

1. to determine the psychometric properties of the tool;

2. to determine the feasibility and acceptability of using the UpStart Parent Survey in PFPPs; and

3. to examine parental perceptions of program impact using the UpStart Parent Survey.

This article reports on the latter two purposes. 
International Journal of Child, Youth and Family Studies (2013) 1: 119-135

\section{Methods}

The Building Safe Communities from the Start: The Upstart Parent Survey study was a mixed-methods design, conducted in a major urban centre in Western Canada between June 2010 and April 2011. It was cleared by both Mount Royal University's Human Research Ethics Board and University of Calgary’s Conjoint Health Research Ethics Board.

Participating parents were accessed through existing parenting programs. Agencies providing these programs volunteered to be part of the study. The parenting programs participating in this project were diverse. All programs were stable with established curricula. The programs varied in length from 4 to 11 weeks, with weekly classes that lasted between 2 to 3 hours. The major focus of the programs was parenting education; however, each program was tailored to specific parenting populations, including first-time mothers, parents with low income, and parents new to Canada. Programs targeted parents of children 6 years of age and under. Program components varied, but all programs included facilitated parent discussion and learning in a classroom setting. Some programs included both parent and child sessions where parents could learn by observing and engaging in age-appropriate learning activities with their own child and other children from the program. Common aspects of all curricula were knowledge of child development, effective parenting strategies, as well as information on additional parenting resources such as educational literature, websites, and other community programs and resources.

Six agencies providing seven programs participated in the Building Safe Communities from the Start study. Primary contacts for the project were the agency program managers, that is individuals responsible for decision-making and administration of the programs. Program facilitators were staff from each of the agencies; facilitators were responsible for the delivery of the program to the parent groups.

Three hundred and fifty-four parents or caregivers of young children participated in the study by completing the UpStart Parent Survey. Participants ranged in age from 18 to 50 years; $90 \%$ of participants were female. The majority of participants were married (70\%); 12\% had less than a high school diploma and $79 \%$ had some amount of post-secondary education. Average household income was under $\$ 80,000$ per year for $48 \%$ of participants. Nearly $30 \%$ of the participants self-identified as non-Caucasian and the vast majority (87\%) had either one or two children.

\section{Measures}

Data used to determine the feasibility of the survey were gathered through a single-item question on the UpStart Parent Survey, two focus groups with parents, one focus group with program facilitators, and a capacity-building workshop with program managers. Program outcomes for participating programs were measured using the UpStart Parent Survey - an evaluation tool with a retrospective pre-test design containing both closed and open-ended questions. It is a paper and pencil, self-report survey that takes approximately 15 to 20 minutes to complete. The participants' responses to the open-ended questions about what they had learned and changed in terms of their parenting were thematically analyzed through the lens of promoting safe communities, a key area of concern for one of the funders. 
The quantitative component consists of three subscales: Parenting Knowledge and Skills (i.e., typical child growth and development, discipline strategies, child health and safety, and dealing with everyday challenges); Parenting Experience (i.e., parenting confidence, formal and informal social support, emotional health, and stress management); and Program Satisfaction (i.e., parent satisfaction with the attended program).

The Parenting Knowledge and Skills Scale and the Parenting Experiences Scale have a retrospective pre-test design with a 7-point Likert scale and a "not covered" response option. Participants respond to each statement twice, once with a "today" score and then with a "before this program” score for each item. The Program Satisfaction Scale is a 5-point Likert scale measuring the parents' satisfaction with the program. A series of demographic questions are followed by a single-item question asking participants to rate the difficulty of completing the survey with the choices of "easy", "average”, or "hard”.

The qualitative component of the survey contains three open-ended questions at the end of the survey known as "the 3/2/1 questions": three things I have learned from this program; two things I have done differently because of this program; and one thing I still have a question about. In addition, parents were asked for any suggestions to improve the program. These questions were developed collaboratively by program administrators for quality improvement purposes. Qualitative data, using a set of structured questions, were collected from two focus groups with parents and one focus group with program facilitators. Structured questions were used to focus the discussion about using the survey at the capacity-building workshop with program managers.

\section{Procedure}

The project team initially met with program managers to review the project goals, outline the process, and distribute the materials including UpStart Parent Surveys, a program summary form, and an instruction script for the program facilitators. Program managers subsequently met with their facilitators about the UpStart Parent Survey project to gain their support and assistance, and reviewed the process and forms. Parent participants were asked to complete the UpStart Parent Survey at the end of the last class of their parenting program. After distributing the surveys, facilitators read out the instruction script and were present to answer any questions. The program facilitator then compiled all surveys with a program summary form and mailed them to the principal investigator of the project. Only program names were identified on the survey forms; no participant names were collected.

Two parent focus groups and a facilitator focus group were held part way through the study. All parent participants and facilitators involved with the study were invited through flyers and promotion at each participating agency. All participants were provided with information about the purpose of the focus groups, gave their informed consent, and understood that they would be guaranteed confidentiality. For all focus groups, qualitative data were collected to address the format and feasibility of the survey: ease of implementation and completion, challenges and benefits of the survey, and parent and facilitator willingness and comfort in completing and administering the survey. The focus groups were digitally recorded and notes were made on flip charts during the conversation to enable participants to confirm the accuracy 
International Journal of Child, Youth and Family Studies (2013) 1: 119-135

of the notes or to clarify their comments. Audio recordings were transcribed and the data were analyzed thematically to determine parents' and facilitators' view of the feasibility of the UpStart Parent Survey. Only aggregate comments or comments that did not contain identifiers were used in any written reports (for example: "We eat supper together as a family”).

A capacity-building workshop for program managers was held at the completion of survey data collection. All participating agencies were invited to attend. The workshop was facilitated by an external consultant and its purpose was to present the aggregate and confidential agency program evaluation reports, and to get managers' feedback on the feasibility of the survey. Comments were recorded on a flip chart to ensure accuracy and for purposes of clarification, and a summary with documented comments was reported back to the project team. A follow-up managers' meeting was held two months later and a summary of participant comments were recorded in the meeting minutes.

\section{Results}

Parent responses to the UpStart Parent Survey question asking them to rate the difficulty of completing the survey (i.e., easy, average, or hard to complete) indicated that the survey was relatively easy (i.e., 97\%) to complete.

Two parent focus groups were conducted by the student research assistants with a total of ten parents from two different agencies. While all parents who participated in the study were invited, parents only attended if a focus group had been organized by their specific agency. Parents in the two focus groups differed demographically; one group had four parents with low literacy and the second group had six “mainstream” parents.

The survey was well received by parents and many indicated the importance of completing a survey or evaluation after finishing a parenting course. Parents suggested that the survey both allowed for self-reflection relating previous knowledge to current knowledge, and was thought provoking with respect to items they still had questions about. One parent said:

The survey kept everything a little more clear and opened up a few more questions that I actually brought up with the facilitator later.

Challenges identified with the survey included the length of the survey and the time it took to complete. Parents made some suggestions that would have better supported them in overcoming these logistical challenges:

I'm thinking people should be prepared and aware this is going to take time. So you make time for it.

Parents indicated that the format and language of the survey was clear and they understood what the survey was asking. Some parents suggested that, initially, the retrospective design was not easy to follow; however, once the facilitator had explained 
International Journal of Child, Youth and Family Studies (2013) 1: 119-135

how to complete the questions and the purpose of the retrospective design, parents had a better understanding of the concept:

They are trying to gauge where you were at the beginning and how much you grew.

All program facilitators were invited to a focus group conducted by the principal investigator and student research assistants. Only two facilitators were able to attend; however, the conversation was lively and provided very helpful information for the project. Facilitators were asked to comment on the opportunities, challenges, and logistics presented by the UpStart Parent Survey.

When asked about opportunities presented by the survey, one facilitator commented that the open-ended 3/2/1 questions in the survey were very useful as parents' answers were detailed, clear, and informative. The other facilitator found, however, that these questions were difficult to explain to parents with English as a second language. This facilitator commented that the closed questions were more appropriate for her parents as they helped her determine if she had covered all of the required topics with parents.

Facilitators were asked about the challenges presented by administration of the UpStart Parent Survey. Both facilitators suggested that there were varying levels of understanding of the survey by participating parents. When parents with English as their second language or low literacy required the facilitator to provide a verbal explanation of a specific question, the meaning of the question may have changed thus potentially altering the participants' responses. This additional explanation may also lead parents to look for the right answer from the facilitator. One facilitator also wondered whether cultural understandings of different words may have altered the meaning of the questions and thus of the responses.

The retrospective design of the study did cause some challenges for some parents, particularly those in one group who live with Fetal Alcohol Spectrum Disorder (FASD). However, both facilitators felt that, once this design was explained, parents understood and were able to complete the survey relatively easily.

The program facilitators were asked to discuss the logistics of administering the survey. One facilitator explained that she anticipated that the survey might take considerable time for the parents to complete so she planned for $\mathbf{4 5}$ minutes at the end of the last session. In addition, she had arranged a potluck meal to celebrate the conclusion of the program so it gave everyone time to talk more about both the program and the use of the survey. The other facilitator, however, did not anticipate the need to provide significant time at the end of the last session; therefore, the parents in her program were rushed to complete the survey. She also realized that she had not provided a suitable setting for parents to complete the survey; parents had to write on their laps, sometimes holding a child at the same time. This rush at the end of the session also meant that she did not have time to discuss how the parents felt about the survey questions or the process of completing the survey. 
International Journal of Child, Youth and Family Studies (2013) 1: 119-135

Both facilitators followed the provided instruction script and found it to be helpful. One facilitator, whose participants all speak English as a second language, found the need to explain the survey page by page but, as she had allotted the time, it worked reasonably well. Both facilitators commented that when they collected the surveys, they were careful to place them face down to protect privacy so there was no appearance of reading the answers with the parents still in the room. Neither facilitator heard any negative comments either about completing a survey or the questions on the survey. As one said, the parents expect an evaluation at the end of a program so this survey was not unusual.

When asked about the impact on their programs of using the UpStart Parent Survey, both commented that the survey provided good information about what had been provided in the program and how parents had responded. They both felt that the survey gave them a strong indication of whether or not they had covered all the topics and how to modify their approach to make it more effective for parents. In addition, the parent responses reminded the facilitators of what they should be emphasizing throughout the program. They also appreciated comments that provided ideas for future groups. One facilitator suggested adding more open-ended questions and also asking about the children's reactions to what parents were learning and doing differently as a result of participation in the program.

At the end of the focus group session, both facilitators commented on how useful the focus group had been for them, both in terms of how to administer the survey appropriately and how to make use of the results.

A capacity building workshop was held with program managers at the end of the study to provide individual and aggregate program evaluation reports from the UpStart Parent Survey data and to support managers in using their individual results to improve their programs. An invitation to attend the workshop was extended to the six participating agencies; four were represented. The workshop was facilitated by an external facilitator.

Following introductions, the aggregate results from all programs compiled to date were circulated; the co-researchers explained the meanings of the aggregate data, the terms used to describe the data, as well as how the data related to each individual agency and their program outcomes. The program managers then had the opportunity to review their individual program reports and ask questions.

Program managers were asked to discuss the logistics of implementing the survey. It appeared that the survey took, on average, about 20 minutes for parents to complete. Most parents completed the survey independently and did not appear to have any difficulties. If parents had questions, facilitators were able to assist. The most challenging questions for parents seemed to be those which asked about their partners and about parenting support. Managers suggested minor changes in wording.

Program managers were then asked about their experience participating in the UpStart Parent Survey project. Managers were appreciative that the project did not compare programs but, instead, provided both individual program and aggregate results to create an "overall view of P-FPPs". They commented that the survey was useful in providing a "before and after" 
perspective for parents and they appreciated that parents could reflect on their "increasing parenting ability and confirm their own personal reflections". Managers commented that parents seemed "willing and able" to complete the survey at the end of their program. While some questions were not applicable to all programs, managers saw their ability to tailor the survey to meet their individual program needs. As the project continues, programs will be able to provide translations and tailor their curricula through the use of the survey.

Generally, managers commented that, while the project required patience as processes for implementing and testing the survey were developed, they felt supported by the researchers and research assistants. Comments about the impact of the survey and the reports included some wanting to use the survey for all of their programs. Managers felt that the survey increased their confidence and program credibility, and encouraged them that they were "now able to show the value of the work" they do. All managers agreed that they were pleased with the results from the survey and, while they acknowledged that there were a few more steps before the survey would be able to be widely distributed, were keen to be able to use the survey on a regular basis in their programs.

\section{Examining the Effectiveness of P-FPPs}

Another purpose of this study was to examine the effectiveness of P-FPPs using the UpStart Parent Survey. Thematic analysis of the qualitative data gathered from the 3/2/1 questions on the UpStart Parent Survey indicated strong themes related to parenting knowledge and skills, parenting efficacy, and the importance of a connection to the community among parents attending a P-FPP, factors demonstrated to mediate the early precursors of later problematic behaviour.

\section{Parenting Knowledge and Skills}

Parenting knowledge and skills are key contributors to child development (Mistry et al., 2002). Parent knowledge of child development shapes overall expectations of and interactions with the children. Parents with little knowledge of child development often overestimate the rate of development, which could potentially lead to inappropriate expectations, impatience, and intolerance (Cowen, 2001). When parents falsely attribute challenging behaviour (such as tantrums) to willful defiance, they are more likely to punish their child for normative, albeit challenging, behaviour (Ateah \& Durrant, 2005). Parent responses to the 3/2/1 questions of the UpStart Parent Survey indicated learning in the following areas of knowledge: (a) child development, (b) nurturing and attachment, and (c) effective discipline.

Knowledge of child development refers to a level of understanding related to emotional, physical, social, and cognitive development of children. Parents identified learning about the ages and stages of their children, and how that learning has affected their parenting, specifically in regard to communication and interactions with, and responses to, their children. Parents described learning about developmental milestones, the physical changes of a growing child, and the importance of providing age-appropriate activities. Parents also identified the value of 
learning that development has a predictable pattern but that their children may regress when under stress, such as when a new baby arrives in the family. This allowed them to be more patient when their children were undergoing new or difficult situations. Parents talked about acquiring skills related to their child(ren)'s development; for example, one parent commented that she learned how to use her new understanding of child development to make the transition from a crib to a bed easier for her child.

Nurturing and attachment focuses on the relationship between parents and their child(ren) (vanIJzendoorn, Schuengel, \& Bakermans-Kranenburg, 2010). Parents identified new knowledge and skills that maintain and strengthen their parent/child relationships while supporting the social, emotional, cognitive, and physical development of their children. Parents talked about learning to build relationships with their children by listening to what their children are trying to say; they also talked about the strategies they had learned to help their children develop positive self-esteem. Parents spoke about the importance of unstructured play and reading to support their children's development; they also spoke about how they had learned to play with their children using songs and movement, and engaging in various play activities by following their child(ren)'s lead. Parents talked about understanding that age-appropriate activities would help to encourage their children's self-confidence. One parent talked about the importance of being a positive role model for her child.

Having knowledge of what to expect at each age and stage appeared to help parents be more patient and increased their confidence in their ability to relate to, and nurture, their children. Parents talked about becoming more sensitive to their children's feelings and being more open-minded towards what their children do and say. One parent recognized that when she responded to the challenges of parenting in a stressed manner, her children might also feel stressed and react accordingly. Another parent referred to having a new view of her family where each member has rights, which led her to think about developing more positive parenting skills. Another focused on how she had learned to understand and give her child a chance to think for himself. Other parents commented:

I tell her I'm proud of her.

I have taken more time to hear what my daughter is "saying”.

I [now] talk to my children about my values which I [had] never done before.

Parents indicated that they had gained a better appreciation of what to expect in terms of typical child behaviour related to development and had learned the importance of ageappropriate expectations of their children. They were interested in learning about more effective ways to discipline their children and talked about implementing new, more positive discipline strategies. One parent commented about learning the importance of taking the time to set guidelines for children so that they understand boundaries and limits. Many parents expressed a greater understanding and skill set for dealing with challenging behaviours and helping to teach their children instead of punishing them. They talked about learning that different types of discipline could be applied in different situations; they further commented that they were learning that yelling and physical punishment (e.g., spanking) was not necessary. The following 
International Journal of Child, Youth and Family Studies (2013) 1: 119-135

demonstrate what parents felt they had learned and how they were implementing that knowledge into their daily practice as parents:

I learned what discipline really is and how to do it.

Integrated new discipline strategies at home that have been effective.

Altered my way of communicating to my children.

Managing tantrums in [the] most productive way for my child [and] myself.

\section{Parenting Efficacy}

Parenting self-efficacy is moderated by the caregiver's knowledge of child development (Reiner Hess, Teti, \& Hussey-Gardner, 2004). Ineffective and hostile parenting is significantly related to increased risk of school failure and of children developing conduct problems which increase the risk for becoming involved in anti-social, aggressive, and offending behaviour (Gardner et al., 2006; O’Connor, 2002).

Many parents expressed that they gained a better understanding of their role as parents and were able to maintain and increase their parenting efficacy through self-awareness, effective communication, and self-care. Parents talked about how important it was to acknowledge themselves as parents - an important role - and to find ways to build confidence in their parenting skills. One parent commented that she was more aware of the different parenting styles she and her partner had and how she was using that awareness to work together with her partner when parenting. Some parents talked about the importance of maintaining communication with others in their families and how communication is different with a partner than it is with children. Several parents commented that they had learned the importance of self-care and different ways of looking after themselves:

My confidence as a parent has improved and I feel so much more capable of enjoying motherhood because of the tools learned in [agency name].

[I] have become more patient [and am] more educated about my child's behaviour.

I gained more confidence not only [in] myself but [in] how [I] take care of my son and family as well.

[I] shared information with my partner so that we can parent together.

\section{Importance of Community}

To build safer and healthier communities, there needs to be a relationship between families and their communities. Social support is a key influence on parenting behaviour, and a 
supportive social network and community can improve the knowledge of parents about child development and increase confidence in their parenting (Crill Russell, Birnbaum, Avison, \& Ioannone, 2011). In addition, parental access to additional social supports has been shown to improve effectiveness of parental learning and the success of parenting programs, improving both parent and child outcomes (Mann, 2008). Through the UpStart Parent Survey, many parents expressed that the P-FPP they attended helped them to gain a better sense of community cohesion and increased their access to resources. Parents also identified that attending a P-FPP provided an opportunity to meet other parents who were encountering the same challenges and successes of being a parent:

\section{I learned that I was not alone in the way I felt.}

Parents expressed that the classes were a safe environment where sharing ideas, concerns, and successes was an opportunity to learn and improve their parenting skills and knowledge as well as validate their current skills and knowledge:

It is a great feeling to know that I can share my concerns when I have [them] and instead of just talking or complaining or worrying together [as a couple], we discuss[ed] with moms and an educator and learn[ed] what to do and how to think [about the situation].

Parents talked about how the parenting group itself became a supportive social network, a community to which they were connected, a place to improve their knowledge and build their parenting confidence:

It addresses things I never even thought of. Knowing that a couple things you are doing, you are doing right...it's not me that is the problem...gave me a positive feeling about what I am doing at home.

Parenting practices, expectations, and cultural norms are different around the world. This creates difficulties for parents when they move from one culture to another, often without their extended families or other familiar parenting supports. Canada has received new families from many diverse cultures as well as diverse family structures and practices. Parents new to Canada commented in the survey how their participation in a P-FPP helped them become more aware of Canadian norms, laws, and expectations related to parenting. Parents from a variety of programs showed a greater awareness of services and resources in Calgary after attending a P-FPP, thereby promoting a sense of community and support:

Parents are human too; we can ask for help.

[I] learned where to go/call whenever I need help.

[I learned about] different agencies to call for support in terms of parenting programs. 
International Journal of Child, Youth and Family Studies (2013) 1: 119-135

\section{Discussion}

This paper reports on the thematic analysis of qualitative data collected to address the feasibility of using the UpStart Parent Survey in P-FPPs and the effectiveness of P-FPPs who used the survey. The study was an initial exploration of the use of the UpStart Parent Survey by P-FPPs, was limited to one major Canadian city, and was conducted over a relatively short period of time. As such, our conclusions are preliminary and require further exploration in other contexts. Analysis of feedback from focus groups with parents and program facilitators, and a workshop and meeting with program managers, indicated that the UpStart Parent Survey appeared to be a feasible tool for P-FPPs in that $97 \%$ of parents found the survey either easy or average to complete and were generally comfortable completing the tool at the end of their program. Facilitators indicated that most parents were able to complete the survey independently or with some assistance and appeared willing to complete the tool.

P-FPPs provide parents an opportunity to normalize the challenges of everyday child behaviour and give families the chance to learn effective parenting strategies to support their child(ren)'s development. P-FPPs are a prevention strategy; consequently, it is difficult to measure "what might have happened" had parents not attended a P-FPP. Thematic analysis of the qualitative data collected through this study indicated that both parents and program facilitators saw improvements in parental knowledge and parental experience/efficacy as a result of attending a P-FPP. However, it is important to note that this was a small initial study conducted in one city. It will be necessary to conduct further studies of the psychometric properties, feasibility, and efficacy of the UpStart Parent Survey by engaging more agencies and parents in different geographic and demographic populations. Long-term studies will be necessary to determine the residual effectiveness of P-FPPs over the course of family parenting, and could more closely examine the impact of issues such as the mental health of family members, parent-child relationships, different family settings, and so on.

Throughout this project, researchers were aware of the need to support the agencies and the facilitators involved in the delivery of the Upstart Parent Survey and the additional components needed for the psychometric testing. While only two facilitators were able to attend the focus group, the sharing between the facilitators was found to be very helpful. As a result of this low participation, the project team requested that the student research assistants visit each of the programs to provide further information, offer support, and elicit any further feedback. Participating agencies, at a follow-up project meeting, indicated that they appreciated this support from the student research assistants and the additional points of clarification they were able to bring from the other participants.

Research clearly shows that effective parenting increases the likelihood that children will grow up to be healthy, productive citizens. Strong knowledge about child development, healthy

parent/child relationships, positive discipline, parent mental health and sense of competency, and social support are key components of effective parenting and should be part of any P-FPP. It is important to know whether parenting programs are achieving these common outcomes; therefore, there is a need for a valid, reliable tool that is feasible for use by both parent participants and program facilitators. This was an initial study; a more in-depth analysis of the psychometric properties of the UpStart Parent Survey is required. 
International Journal of Child, Youth and Family Studies (2013) 1: 119-135

\section{References}

Alberta Centre for Child, Family \& Community Research. (2007). Common outcomes initiative: Roundtable final report. Edmonton, AB: Author.

Armstrong, M. I., Birnie-Lefcovitch, S., \& Ungar, M. (2005). Pathways between social support, family well-being, quality of parenting, and child resilience: What we know. Journal of Child and Family Studies, 14(2), 269-281.

Ateah, C., \& Durrant, J. (2005). Maternal use of physical punishment in response to child misbehavior: Implications for child abuse prevention. Child Abuse and Neglect, 29(2), 169-185.

Benzies, K., Keown, L. A., \& Magill-Evans, J. (2009). Immediate and sustained effects of parenting on physical aggression in Canadian children to 6 years of age. Canadian Journal of Psychiatry, 54(1), 73-82.

Benzies, K., Tough, S., Edwards, N., Nagan, K., Nowicki, B., Mychasiuk, R., et al. (2009). Effects of a two-generation Canadian preschool program on parenting stress, self-esteem, and life skills. Early Childhood Services, 3(1), 19-32.

Canadian Association of Family Resource Programs (FRP Canada). (2011). Family is the foundation. Ottawa, ON: Author. Retrieved from http://www.frp.ca/document/docWindow.cfm?fuseaction=document.viewDocument\&doc umentid=995\&documentFormatId=1731

Cowen, P. S. (2001). Effectiveness of a parent education intervention for at-risk families. Journal for Specialists in Pediatric Nursing, 6, 73-82.

Crill Russell, C., Birnbaum, N., Avison, W. R., \& Ioannone, P. (2011). Vital communities, vital support: How well do Canada's communities support parents of young children? Toronto: Invest in Kids: The Phoenix Centre for Children and Families. Retrieved from http://www.beststart.org/invest_in_kids/pdf/ComVitalityPhase\%202_FINAL_REPORT.p df

Gardner, F., Burton, J., \& Klimes, I. (2006). Randomized controlled trial of a parenting intervention in the voluntary sector for reducing child conduct problems: Outcomes and mechanisms of change. Journal of Child Psychology and Psychiatry, 47(11), 1123-1132.

Griner Hill, L., \& Betz, D. (2005). Revisiting the retrospective pretest. American Journal of Evaluation, 26(4), 501-517. 
International Journal of Child, Youth and Family Studies (2013) 1: 119-135

Kaminsky, J., Valle, L., Filene, J., \& Boyle, C. (2008). A meta-analytic review of components associated with parent training program effectiveness. Journal of Abnormal Child Psychology, 36(4), 567-589.

Kolb, B., Gibb, R., \& Robinson, T. (2003). Brain plasticity and behaviour. Current Directions in Psychological Science, 12(1), 1-5.

Knudson, E. (2004). Sensitive periods in the development of the brain and behavior. Journal of Cognitive Neuroscience, 16(8), 1412-1425.

Lundahl, B., Risser, H. J., \& Lovejoy, M. C. (2006). A meta-analysis of parent training: Moderators and follow-up effects. Clinical Psychology Review, 26(1), 86-104.

Mann, B. (2008). What works for whom? Promising practices in parenting education. Ottawa, ON: FRP Canada. Retrieved from http://www.frp.ca/index.cfm?fuseaction=page.viewpage \&pageid=932

McCain, M. N., Mustard, F. J., \& Shanker, S. (2007). Early Years Study 2: Putting science into action. Toronto: Council for Early Child Development.

McLennan, J. D., \& Lavis, J. N. (2006). What is the evidence for parenting interventions offered in a Canadian Community? Canadian Journal of Public Health, 97(6), 454-458.

Mistry, R., Benner, A., Biesanz, J., Clark, S., \& Howes, C. (2010). Family and social risk, and parental investments during the early childhood years as predictors of low-income children's school readiness outcomes. Early Childhood Research Quarterly, 25(4), 432449.

Mistry, R. S., Vandewater, E. A., Huston, A. C., \& McLoyd, V. C. (2002). Economic well-being and children's social adjustment: The role of family process in an ethnically diverse lowincome sample. Child Development, 73(3), 935-951.

Moore, D., \& Tanais, C. A. (2009). Measuring change in a short-term educational program using a retrospective pretest design. American Journal of Evaluation, 30(2), 189-202.

Nagin, D. S., \& Tremblay, R. E. (2001). Parental and early childhood predictors of persistent physical aggression in boys from kindergarten to high school. Archives of General Psychiatry, 58(4), 389-394.

National Forum on Early Childhood Program Evaluation. (2007). Early childhood program evaluations: A decision-maker's guide. Cambridge, MA: Center on the Developing Child at Harvard University. 
International Journal of Child, Youth and Family Studies (2013) 1: 119-135

O’Connor, T. G. (2002). Annotation: The "effects” of parenting reconsidered: Findings, challenges, applications. Journal of Child Psychology \& Psychiatry, 43(5), 555-572.

Reiner Hess, C., Teti, D. M., \& Hussey-Gardner, B. (2004). Self-efficacy and parenting of highrisk infants: The moderating role of parent knowledge of infant development. Applied Developmental Psychology, 25(4), 423-437.

Rikhy, S., Tough, S., Trute, B., Benzies, K., Kehler, H., \& Johnston, D. (2010) Gauging knowledge of developmental milestones among Albertan adults: A cross-sectional survey. BMC Public Health, 10(1), 183.

Sanders, M., Markie-Dadds, C., Tully, L., \& Bor, W. (2000). The Triple P - Positive Parenting Program: A comparison of enhanced, standard, and self-directed behavioral family intervention for parents of children with early onset conduct problems. Journal of Consulting and Clinical Psychology, 68(4), 624-640.

Scott, S., Knapp, M., Henderson, J., \& Maughan, B. (2001). Financial cost of social exclusion: Follow up study of antisocial children into adulthood. British Medical Journal, 323, 191194.

Shonkoff, J. (2003). From neurons to neighborhoods: Old and new challenges for developmental and behavioral pediatrics. Developmental and Behavioral Pediatrics, 24(1), 70-76.

Sibthorp, J., Paisley, K., Gookin, J., \& Ward, P. (2007). Addressing response shift bias:

Retrospective pretests in recreation research and evaluation. Journal of Leisure Research, 39(2), 295-315.

Stewart, M. J. (2000). Community nursing: Promoting Canadians' health (2nd ed.). Toronto: W. B. Saunders.

Tremblay, R., Nagin, D., Seguin, J., Zoccolillo, M., Zelazo, P., Boivin, M., et al. (2004). Physical aggression during early childhood: Trajectories and predictors. Pediatrics, 114(1), 43-50.

vanIJzendoorn, M. H., Schuengel, C., \& Bakermans-Kranenburg, M. J. (2010). Disorganized attachment in early childhood: Meta-analysis of precursors, concomitants, and sequelae. Development and Psychopathology, 11(1999), 225-249.

Webster-Stratton, C., \& Reid, M. (2003). Treating conduct problems and strengthening social and emotional competence in young children: The Dina Dinosaur Treatment Program. Journal of Emotional and Behavioral Disorders, 11(3), 130-143.

White, A. (2005). Assessment of parenting capacity: Literature review. Ashfield, New South Wales, Australia: Center for Parenting Research. 